\title{
Patents Used for Treating Solid Granular Wastes, Coming from The Automotive and Mining Industry
}

\author{
Torres JV* \\ National Institute of Nuclear Research, Mexico
}

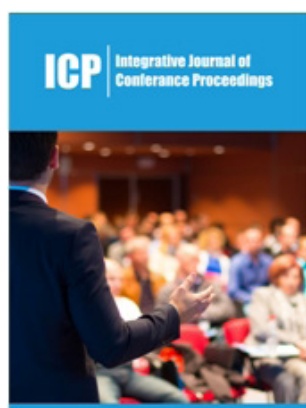

*Corresponding author: Torres JV, National Institute of Nuclear Research, Mexico

Submission: 侮 May 23, 2019

Published: 此June 04, 2019

Volume 1 - Issue 3

How to cite this article: Torres JV. Patents Used for Treating Solid Granular Wastes, Coming from The Automotive and Mining Industry. Int J Conf Proc.1(3) ICP.000515.2019.

Copyright@ Torres JV, This article is distributed under the terms of the Creative Commons Attribution 4.0 International License, which permits unrestricted use and redistribution provided that the original author and source are credited.

\section{Introduction}

Granular solid residuals are produced by different industries in Mexico. Some of these are considered dangerous because they are stored in open areas contaminating and affecting the flora, fauna, and aquifers, and occasionally to the human being. These solid residuals coming from mines and diatomaceous earth are known as jales (náhualt derivated from xalli, it means sand). The jales have a high content of cyanide and heavy metals. These high contents are commonly out of the limits permitted by the Mexican standards. On the other hand, the "diatomita" (diatomaceous earth) is not as dangerous as the "jales", however, this needs a treatment to eliminate the occluded organic material. This is normally used by producers of gelatin, antibiotics, industrial grease and oil, sugar refining, etc.

The leaching process of metals using the sodium cyanide was introduced in $1887 \mathrm{Li}$, 1993. This revolutionizes the techniques to obtain gold and silver. This is a method usually employed in the world to recover metals. Two international patents were obtained by developing equipment and a process to extract toxic metals and wastes from foundry sands Vite, 1994a, 1994b. In addition, a national patent was achieved by the leaching of heavy metals from foundry sands Vite, 1997. The mechanical properties of these ceramic materials, such as the compressive strength were determined in accordance to ASTM C170-50 and ASTM C-36 standard. The results showed that these ceramic materials are lighter and exhibit higher compression strength than conventional materials such as bricks.

\section{Background of the invention}

The invention refers to an apparatus and process for extracting metals from foundry sands and, more specifically, to an apparatus and process for extracting these metals by making use of a thermostated column. In the field of metal extraction based on foundry sands, the extraction techniques most utilized to date in a liquid-solid system involve mechanically stirred leaching tanks, the Pachuca (State of Mexico) tank and Bonotto, Kennedy or Rotocel extractors. None of this equipment however has been specifically designed to extract small quantities of metals from foundry sands, which represents a problem not, so far, resolved.

Of the conventional apparatus mentioned above, the Pachuca tank is that which most resembles the apparatus object of the present application. However, the thermostated column of the new apparatus differs from the Pachuca tank insofar as regards its air dispersion system, the use of decarbonated and humidified air, because it consists of a heating jacket and because temperature control of the heating fluid is by means of a thermostat. These features of an apparatus which is desired to protect, allow a suitable pulp suspension, prevent the formation of a silicate and carbonate layer at the bottom of the column, permit better temperature control and a finer control of the process variables, such as the $\mathrm{pH}$, the air flow and the solution's oxidation-reduction potencial.

\section{Summary of the apparatus}

The apparatus and the process of the present invention allow low concentrations of the metals contained in the mining tailings to be simultaneously extracted, thus achieving two main goals which are 1) the recovery of metal values which can be recycled and 2) An 
important reduction in the toxicity of the industrial solid wastes ( Mining Tailings) which once treated, can be handled as normal industrial waste, which can be used to make ceramic materials or construction materials, with important savings. From among the metals which are possible to recover, one can mention, among others platinum, gold, cobalt, germanium, zinc, manganese, silver and cooper, metals with many industrial uses, and some others such as chromium, vanadium and arsenic, which are highly toxic.

In order to achieve its purpose, the apparatus consists of a thermostatic includes column which is connected to a decarbonated and humidified air supply source, and with a controlled heating system. This column includes an inlet for introduction of the components to form an aqueous pulp, and device for sparging, it in such a way that a suitable suspension and homogenization of same is obtained. For its part, the process is characterized by the introduction into the column of some reagents, distilled water and industrial solid wastes (mining tailings) in order to form an aqueous pulp which is processed in same for 2 hours under controlled temperature, air flow and $\mathrm{pH}$ conditions. Upon termination of the above-mentioned period, the pulp in the column is extracted and once again heated for 20 minutes, after which it is filtered in order to obtain liquor with the metals in solution. Another distinctive characteristic of this process is that, as distinguished from the existing system, it permits the extraction of metals from metallic alloys; the thermodynamic stability is higher than covalent bonds.

\section{Treatment of the Mining Industrial Residuals samples} (MIR)

To determine the presence and concentration of cyanide and heavy metals, representative samples were analyzed qualitative and quantitatively using conventional and nuclear techniques. Then, the content of cyanide was removed using thermostated coupled columns. This process and the equipment were developed and patented in the United States and Mexico (Vite, 1994a, 1994b). Samples are placed into the equipment, where sodium hypochlorite is added, the temperature in the columns is set at $28{ }^{\circ} \mathrm{C}$, during 20 min. Once the process is completed, the separation solid liquid is performed. Then, the solid sample is dried and placed back in the thermostated coupled columns in order to leach heavy metals. The sample of "jales" is mixed with reducers, surfactants and complexing agents to perform the leaching process at different $\mathrm{pH}$. Then, an acid or a base is added, la pulp is stirred by injecting air and each sample is processed for $120 \mathrm{~min}$. at $60{ }^{\circ} \mathrm{C}$. After all this process, the solid-liquid separation is made. The solid was sieved to obtain a grain size between $100-200 \mu \mathrm{m}$ and was analyzed qualitative and quantitatively, in order to verify the decrease in the concentration of cyanide and heavy metals content in the samples, if there is any evidence of a toxic component, the operation is repeated until obtain innocuous samples. The treatment of solid residuals to leach cyanide and heavy metals was successful, as it eliminates $100 \%$ of the cyanide content, as well as $80-100 \%$ of the heavy metals content occluded in the chemical matrix of the sample.

\section{Specimens}

The materials used to conduct the tests were ceramic materials identified as Jadiar due to a mixture of Jale-Diatomaceous earthClay. The samples were named as $1 \mathrm{~A}, 1 \mathrm{~B}$ and $1 \mathrm{C}$. In the sample $1 \mathrm{~A}$, $50 \%$ was material coming from diatomaceous earth, $40 \%$ of mining industrial residual (Jale) and 10\% clay. In sample 1B, was used $50 \%$ of diatomaceous earth, $30 \%$ solid residual (jale) and $20 \%$ clay. Finally, in sample 1C, the contents were 50\% diatomaceous earth, $20 \%$ mining industrial residuals and 30\% clay. Each sample was mixed separately and was heat- treated first to remove moisture in an oven at a temperature of $100{ }^{\circ} \mathrm{C}$ for $120 \mathrm{~min}$., then the sample was treated in an oven at $950^{\circ} \mathrm{C}$ for $180 \mathrm{~min}$. 